\title{
Influence of Project Design Factors on Performance of Green Technology Market Projects in Meru County, Kenya
}

\author{
Silas Dennis Barasa and Reuben Wambua Kikwatha
}

\begin{abstract}
Green Technology Market projects have immensely developed in the $21^{\text {st }}$ Century with global spotlight on design of green techniques for preservation of farm produce and Environmental conservation at the market. However, the pragmatic literature posits that they plan on huge budgets and yet mainstream of the projects have aborted in less than five years. Perhaps, the project drivers are not well expressed at the design phase obstructing their performance. In the light of this, study seeks to establish the influence of project design factors on the performance of Green Technology Market projects in Meru County, Kenya. Design factors under study are infrastructure, Stakeholders' Involvement, Quality management practices and beneficiary Selection. The study was found on theory of Value-Belief-Norm and Environmentally Responsible Behavior. The sample size was 85 total populations of 204 sampled using stratified random sampling criteria. Questionnaires were administered to collect primary data. Descriptive statistics and multiple regressions were utilized. The multiple regressions established the influence amid variables. The results across the area of study on major gaps were analyzed. The data was tabulated for presentation. There was a spike in years of operation of Green Technology Market Projects for the last five years. Traders share facilities at the market. Traders accessed quality facilities at the market. Furthermore, to great extent traders comprised of project committee identified in fair process and had knowledge and skill on project design. Locals supplied labor needed in the project design where beneficiary's selection was fair prioritizing the local traders and also tenders were awarded to locals. The study also found that traders accessed quality of services. The study initiate that a unit increase in project infrastructure would lead to 0.067 increase in the performance of Green Technology Market Projects in Meru County, Kenya; a unit change in beneficiary's selection would lead to 0.050 increase in performance of the project; a unit change in the score of stakeholders' involvement would lead to a 0.046 change in performance of the project and a unit change in the score of quality management practices would lead to a 0.040 change in performance of the project. The variables were significant since p-values were more than 0.05 and alternative hypothesis were accepted while the values for F-calculated were greater than $\mathrm{F}$-critical (4.001). The study concluded that project infrastructure had the greatest influence, followed by stakeholders' involvement, Quality Management Practices while Beneficiary's selection had the least influence on the performance of Green Technology Market Projects in Meru County, Kenya. The study also recommends that market designs should embrace greener technologies such as harness of solar energy through roofing of markets with solar panel materials, proper waste disposal with biogas production
\end{abstract}

Published on November 16, 2020

Silas Dennis Barasa, University of Nairobi, Kenya. (corresponding e-mail: silasdennisbarasa ${ }^{\circledR}$ gmail.com)

Reuben Wambua Kikwatha, University of Nairobi, Kenya

(e-mail: kikwathar@yahoo.com) technologies from green wastes, proper clean water supply, proper parking and green landscapes for aeration, adequate refrigeration facilities to preserve Agri-foods from yield loss hence enhancing food security for growing population and achieve poverty reduction as a key focus in the sustainable development goals and also achieve the Big Four Agenda of the Kenyan Government.

Index Terms - Beneficiary's Selection, Green Technology Markets, Project infrastructure, Project infrastructure, Stakeholders' involvement, Quality Management Practices, Project Design.

\section{INTRODUCTION}

In consequence of spiraling universal ecological impacts caused by global warming, environment change, Green House Gases and depleting green energy outputs, green technology has hit the global timelines as a technique for growth of economies with priorities in modern design of market projects for worldwide perspective. Pragmatic literature insinuates that such technologies are directly proportional to achievement of sustainable development goals across the globe changing the mankind's intention towards the environment for both the present and future society [1]. The green technology markets are highway to reducing post harvest loses of Agricultural products awaiting for sell at the farmer's market

In Kenya, [2] posits that a major blueprint project through Economic Stimulus Programme (ESP) was designed to improve employment and spur rural development. Therefore, this implies that conventional market structures such as farmers' stand, open air markets and direct sale are inadequate form of market projects for horticultural traders in Kenya and one has to shelter under Green Technology Markets for efficient display and linkage with end consumers of their fresh produce.

Globally, markets have grown extremely in United States from 1994 to a tune of 8,268 markets in 2014 with farmers selling fresh farm outputs whereas, in Oregon about 62 markets were launched but 32 closed, the findings concluded, that increasing attractiveness was directly proportional to collapse rate [3]. [4] initiate that market projects collapse due to factors such as poor management style, inadequate capital outlay, minute size, and inexpert managers. They further confirmed that Farmers Market in Boston reported a 50 percent fall in turnout as in 2017. The design of green technology markets is vital, and all stakeholders need to focus on sustainability of such projects. 
In Africa, [5] reports over 500 million small scale farmers globally who produce a considerable $80 \%$ of the food utilized in African and Asian market stalls. [6] study on Farmers' markets in US, acknowledged that markets entail farm stands and multiple farmers' stalls selling food for wholesale products such as fresh fruits, cereals and vegetables at the market place. Based on [7] the axle objective is to eradicate poverty, alleviate standard of living through sustainable economic growth and strengthen efficiency service delivery to citizens. These include the establishment of metropolitan greener markets and stalls for trade in the region [8]. Market stalls are focal point where trade takes place in Kenya and the devolved governments have to strategize and put more funds in such projects for they enhance economic development through trade and they are key source of revenue to both rural and urban counties.

In Kenya, about $50 \%$ of poor populations nationally are disposable purchasers of fresh horticultural food from markets with expenditure of $50-70 \%$ of total consumption annually. Furthermore, $68.3 \%$ of fresh horticultural food utilized in Kenyan peri-urban segments originates from purchases whereas their counterparts in hinterlands and rural regions consume about $57.4 \%$ of fresh horticultural food. Food insecurity is a stumbling block to Kenyan Government and feeding its population is key to her well thought plan in the Big Four Agenda [9]. Significantly, majority of the population in Kenya depend on markets as food basket where they buy fresh horticultural food and the Government has to substantially support the Green Technology Market Projects to conserve the produced food awaiting sale at the market.

[10] In their study on Farmers' Markets: Consumer Trends, Preferences, and Characteristics in USA observed that $1 \%$ of participants in the survey obtained their groceries through advertisement, 92\% had identified from farmers' markets, $33 \%$ express farm markets and finally $22 \%$ from other facilities. [11] Posits that over years there is increased demand for freshly produced fruits, cereals and vegetables owing to high demand for tasty, juicy, high flavored and nutritionally viable fruits hence prolific production and marketing. Therefore, we need to design robust green technology market facilities for farmers to refrigerate produce thus sell their produce directly to consumers and fetch high prices.

Project Performance is an essential project management issue and project design is among essential topics discussed. A project includes an enterprise that utilizes raw materials to output desired products with the confines of schedule, budget to achieve the expected timelines of stakeholders. In another discourse a project entails inputs to produce outputs for the target population for certain timeline [12]. On contrary, [13] critics that projects include funding of governmental infrastructure facility like Markets and other micro-enterprises. Critically, a project is an investment that calls for human capacity, capital investment, Favorable business environment and non human capacity in the design of Green Technology Market Projects.

In East Africa, Karatina green technology market in Kenya is the largest of all markets and second in Africa. The market was designed under the Economic Stimulus Project (ESP) with a budgetary allotment of close to Sh 265 Million which was later refinanced to a tune of Sh 367 Million. The design specification of the market was to host over 3000 stalls with daily sales generating income to the economy[14] posits that market places has setbacks such as facing poor storage facilities, overcrowding of traders, lack of clean water, inadequate sewerage system, frequent crime, and environmental dilapidation. However, [15] supports the argument that enhancement of market right of entry is directly proportional to increased trade and eventually amplified proceeds.

\section{A. Statement of the Problem}

In the $21^{\text {st }}$ century, design of Green Technology Market projects face hindrances than success due to poor infrastructure facilities, poor quality management practices, inappropriate project beneficiary selection, and finally poor composition of project stakeholders. Study by [16] only focused on monitoring, evaluation and implementation of market projects. [17] The study illuminated on the variety of farmers' market projects. These studies did not focus on combined project design factors under study. Therefore, the current study fills the gap by establishing how the project design factors such as project infrastructure, stakeholder involvement, project beneficiary selection, quality management practice and how they influence the performance of the green technology market projects in Meru County, Kenya.

\section{B. Research Objectives}

This study sought to investigate the extent to which the combined project design factors (Project Infrastructure, Stakeholders' involvement, Project beneficiary selection and Quality Management Practices) influence the performance of Green Technology Market Project in Meru County, Kenya.

\section{LITERATURE REVIEW}

\section{A. Performance of Green Technology Market Projects}

Green Technology Markets (GTM) is an antique technique in trade with tremendous transformation of farmers market. [18], argues that incursion of novel markets, is decisive to incorporate obstacles encountered by market authorities. Similarly, a study by [19] revealed that to unbutton market entrance to micro-enterprises is a plausible idea however such projects catch upwith several shortcomings which include poor infrastructure facilities, inadequate information on markets, incompetent managers, poor skills on quality standards, incomplete structure designs, and poor managerial support, leading to inappropriate use of some markets in Nigeria and South Africa.

Furthermore, in Kenya, the [20] prioritized to upgrade the following markets Wakulima market the largest in Nairobi County, Kongowea market large with 1,500 stalls in Mombasa, Gikomba, Kariakor, Muthurwa, Marikiti among others. Sincerely speaking, the Performance of green technology market projects is directly proportional to infrastructure investment and resource build up by project donors. 
B. Project Infrastructure and the performance of Green Technology Market Projects

[21] Identified infrastructure as material constituent of coupled systems which supplies commodities and social amenities indispensable to uphold a communal living. [22] Studied the liaison linking project infrastructure and growth and instituted affirmative and considerable attachment. Therefore, proficient, and inexpensive infrastructural services play a key role to the higher performance and output growth of any Green Technology Market project.

[23] Agrees that Infrastructure speculation is an imperative dynamic power to accomplish rapid and persistent fiscal enlargement. For sustained economic growth adequate infrastructure facilities are absolutely imperative in any country.[24] Experiential literature unveils that infrastructural expansion is vital to social and economic growth of all sectors of the economy hence; nations have to create mechanism to mobilize resources and capacitate its population with huge development projects for revenue income, create job opportunities, build wealth, and also improve on human resource.

\section{Project Beneficiary's selection and the performance of Green Technology Market Projects}

Project beneficiaries get selected by recognition of patriotic end-consumer or Motivation of beneficiaries will be a way of fueling the fanaticism in them to get involved in influencing the performance of Green Technology Market Projects. The study findings by [25] on Project sustainability in Kenya indicated that project beneficiary's needs analysis is important in project beneficiary selection. While agreeing with this finding, [26] critics that diverse cluster of citizens opt for differentiated needs in a project thus need for clustering such needs based on urgency. Progressively, benefactors need to rally their needs in a project and have time to speak their minds about the project for this will enhance ownership and sustainability of the project. Therefore, the community participation forms part of project beneficiary selection process and it is decisive in the success of any project.

\section{Quality Management Practices and the performance of Green Technology Market Projects}

QM is a viewpoint with a scientific point of view focused on organizational improvement in terms of service delivery at all stages of project execution. This can only be achieved through understanding and reducing extra work, save on time, reduce on cost, increase on quality features and finally meet customers' expectations [27]. [28] further expounds that quality management (QM) is an attitude of incessantly civilizing the excellence of the goods, services, methodology by prioritizing client's needs and desire and firm's presentation in any project.

[29] also insinuates on the rationale of conniving projects with QM platforms is to enhance consumer contentment, add value to commodities, proper management of production process, staff credibility, improve on sales volume, sharp completion, quality lifespan of projects and finally reduce damages and project costs.

\section{E. Stakeholder involvement and the performance of Green Technology Market Projects}

Involvements by project stakeholders entail considerate association in the supervisory role accounting for views of all parties in the project mandate whereas [30] argues that ever since the independence of the country the Kenyan government initiated reforms for decentralization aiming at integrating mass people in development process. Therefore, Stakeholder involvement is regarded as one of the foundation for first-class governance. It helps to enhance liability, fluency and ensure sustainability of development initiatives such as green technology design projects.

Furthermore, [31] identified that donors in a project have a solemn role of keeping the project on track, financial accounting, monitoring \& evaluation, and finally forecasting project cycles. They organize for strategic meetings, solve conflicts, allocation of workload, and control both human and capital expenses in the project.

\section{F. Theoretical Framework}

The Value Believe Norm Theory of Environmentalism and the Theory of environmentally responsible behavior (ERB)are pertinent in explaining the affiliation between project design factors and the performance of Green Technology Market Projects in Meru County, Kenya. Put forth by Paul Stern in 1999 on environmental paradigm mirrored on personal values, culture, believes, behavior and individual character towards environment. Stern further proposes that human beings need appropriate skills, knowledge, techniques, and resources to protect nature. Ideally, the theory fits in the study by enhancing sustainability of the green technology in performance of their projects. In line with the theory project infrastructure is central design factor.

[32] Proposed the theory based on individual's right behavior can act either for or against the environment. The ERB argues that such behavior includes right attitude, stability, sensitive to act, skills on environment and finally individual mindset towards surrounding.

The current study agrees with the ERB where responsibility to protect the environment can be attained through affordable and clean energy technologies with less pollution to ecosystem, instill training on good environmental behavior to individuals to enhance sustainability.

\section{G. Conceptual Framework}

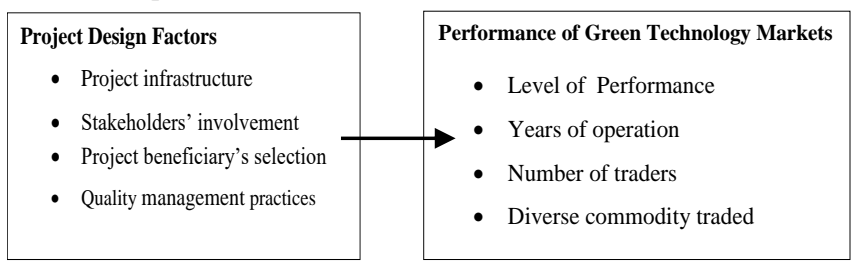

Fig. 1, Conceptual Framework,

\section{Methodology}

The study was coil on pragmatism paradigm approach entwined on philosophical worldview of positivism and participatory underpinnings. Descriptively, the study was designed on cross-sectional survey and correlational survey 
approach that helped to avail explanation for liaison among variables through inferential analysis. The sample size was 85 and total populations of 204 sampled using stratified random sampling criteria. Questionnaires were administered to collect primary data and variables measured by providing respondents with statements rated on a five point Likert scale of equidistance of 0.5 ranging from Strongly Disagree (SD) $1<\mathrm{SD}<1.5$; Disagree (D) $1.5<\mathrm{D}<2.5$; Neutral (N) $2.5<\mathrm{N}<3.5$; Agree (A) 3.5<A<4.5; and Strongly Agree (SA) $4.5<\mathrm{SA}<5.0$. Validity was improved by opinion from experts and conducting a pilot study. Content validity was realized through pilot testing results with comparison on objectives against the research instruments. The researcher embraced the test and retest method within two weeks to confirm reliability of the study where a Cronbach $\alpha$ (Alpha) reliability coefficient for the study was $\alpha>0.7$, the research instrument was adopted. Descriptive statistics and inferential statistics were utilized whereas qualitatively open-ended questions were analyzed using conceptual content analysis method. The descriptive statistics included dispersion, central tendency, frequency distributions and percentages were used to analyze the scores distribution, whereas hypotheses were tested using inferential statistics. The simple linear regressions established the influence amid variables. The results across the area of study on major gaps were analyzed objectively using statistical packages SPSS version 25 . The data was tabulated for presentation.

The following regression models guided the data analysis with the variables and the indicators denoted as follows:

Performance of Green Technology Market Projects $=\mathrm{f}$ (Project Infrastructure, Project beneficiary Selection, Stakeholder Involvement, Quality Management Practices):

$$
Y=\beta_{0}+\beta_{1} X_{1}+\beta_{2} X_{2}+\beta_{3} X_{3}+\beta_{4} X_{4}+\varepsilon
$$

\section{FINDINGS AND Discussions}

The demographic profiles in terms of gender, age group, highest level of education, and years involved in Green Technology Market projects were collected and results tabulated.

TABLE 1: RESPONDENTS' GENDER

\begin{tabular}{ccc}
\hline & Frequency & Percent \\
\hline Male & 21 & 35.0 \\
Female & 39 & 65.0 \\
Total & $\mathbf{6 0}$ & $\mathbf{1 0 0 . 0}$ \\
\hline
\end{tabular}

The findings show that $65.0 \%$ of the respondents were females whereas $35.0 \%$ were males. This depicts that a larger percentage of females participated in the study in relationship to a relatively smaller number of males. In spite of this slight discrepancy, there was no form of gender bias throughout data collection process.

\begin{tabular}{ccc}
\multicolumn{3}{c}{ TABLE 2: RESPONDENTS' AGE BRACKET } \\
\hline & Frequency & Percent \\
\hline$>$ 25 years & 19 & 31.7 \\
$25-35$ years & 28 & 46.7 \\
36 - 45 years & 4 & 6.7 \\
<45 years & 9 & 15.0 \\
Total & $\mathbf{6 0}$ & $\mathbf{1 0 0 . 0}$ \\
\hline
\end{tabular}

The study observed, most of the respondents (46.7\%) were between 25 and 35 years, $31.7 \%$ of them were below 25 years, $15.0 \%$ were above 45 years whereas only $6.7 \%$ of them were between 36 and 45 years. The respondents were not normally distributed; they were of reasonable age to provide relevant information.

\begin{tabular}{ccc}
\multicolumn{3}{c}{ TABLE 3: LEVELS OF EDUCATION } \\
\hline & Frequency & Percent \\
\hline Post Graduate & 7 & 11.7 \\
Undergraduate & 16 & 26.7 \\
Diploma & 8 & 13.3 \\
Certificate & 23 & 38.3 \\
Any other & 6 & 10.0 \\
Total & $\mathbf{6 0}$ & $\mathbf{1 0 0 . 0}$ \\
\hline
\end{tabular}

The findings reveal that $38.3 \%$ of the respondents had attained a certificate, $26.7 \%$ indicated that they had attained undergraduate level of education, $13.3 \%$ had indicated they had reached the Diploma level, $11.7 \%$ had reached a post graduate level while $10.0 \%$ had attained other form of education. This implied that all of them were educated even though at different levels. From this information, it was concluded that they understood the language that was utilized to collect the data thereby they provided reliable information on subject under study.

\begin{tabular}{ccc} 
TABLE 4: YEARS INVOLVED IN GREEN TECHNOLOGY MARKET PROJECTS \\
\hline & Frequency & Percent \\
\hline Below 1 year & 1 & 1.7 \\
1-2 years & 15 & 25.0 \\
3-4 years & 22 & 36.7 \\
Above 5 years & 22 & 36.7 \\
Total & $\mathbf{6 0}$ & $\mathbf{1 0 0 . 0}$ \\
\hline
\end{tabular}

The findings indicated that $36.7 \%$ of them were involved in Green Technology Market projects in Meru County, Kenya for a period of $3-4$ years, $36.7 \%$ indicated for over 5 years, $25.0 \%$ indicated for a period of 1-2 years while $1.7 \%$ indicated for less than 1 year. This implied that most of them had been involved with Green Technology Market projects in Meru County, Kenya for a long period; hence were able to provide information that could be relied upon in the study.

\section{A. Descriptive analysis for Performance of Green Technology Market projects}

Measure of performance was established through a descriptive analysis. Outcomes indicate that the composite mean was 3.530 with a Standard Deviation of 01.195. This indicates a moderate extent of Performance of Green Technology Market projects. The measure of performance (dependent variable) was then associated with the Independent Variables to establish their affiliation and level of influence for the last five years.

\section{B. Descriptive analysis for Project Design Factors and Performance of Green Technology Market projects}

Descriptive analysis was done to determine the relationship between project design factors (project infrastructure, Stakeholder involvement, project beneficiary selection and Quality Management Practices) and the performance of Green Technology Market Projects. The results for project infrastructure indicate a composite mean of 3.312 and a standard deviation of 1.260 which implied a strong association between project infrastructure and the 
performance of Green Technology Market Projects. The Composite Mean of 3.137, standard deviation of 1.367 implied a significant influence between the stakeholders' involvement in projects and the performance of Green Technology Market Projects. The Composite Mean of 3.172, standard deviation of 1.291 implied that the projects beneficiary's selection strongly influence the performance of Green Technology Market Projects. The Composite Mean of 3.181 and standard deviation of 1.273 imply a positive relationship between Quality Management Practices and the performance of Green Technology Market projects.

The following hypothesis was formulated and tested:

Hypothesis H0: The combined project design factors have no significant influence on performance of Green Technology Market Projects in Meru County, Kenya. The hypothesis was tested using the following linear regression model Performance of Green Technology Market Projects = f (Project Infrastructure, Stakeholders' involvement, Project beneficiary selection and Quality Management Practices).

$$
\mathrm{Y}=\beta_{0}+\beta_{1} \mathrm{X}_{1}+\beta_{2} \mathrm{X}_{2}+\beta_{3} \mathrm{X}_{3}+\beta_{4} \mathrm{X}_{4}+\varepsilon
$$

Data was analyzed and the regression result for the influence of project design factors on the Performance of Green Technology Market Projects.

\section{Multiple Regression Results of Project Design Factors} and the Performance of Green Technology Market Projects

Multiple Regression Results of project design factors on the Performance of Green Technology Market Projects shows that $\mathrm{R}=0.555$ implying a positive slope between the independent variables $\mathrm{f}$ (Project Infrastructure, Stakeholders' involvement, Project beneficiary selection and Quality Management Practices) and the dependent variable (Performance of Green Technology Market Projects). The R- Squared was 0.331 meaning that $33.1 \%$ of the variation in the Performance of Green Technology Market Projects was explained by variation in the Project Infrastructure, Stakeholders' involvement, Project beneficiary selection and Quality Management Practices. The other factors explained $66.9 \%$. The ANOVA results indicated that the model was statistically significant at $(\mathrm{F}$ (21.15) above the F-critical of 4.000. The results indicate that the $\mathrm{p}$-value $=0.487, \mathrm{R}$ $=.0 .555$ and $\mathrm{R}$ square $=0.331$. Overall $\mathrm{F}$ statistics was $(\mathrm{F}$ (21.155) shows that there exists a positive correlation and the slope of the population regression line is not zero. Hence based on these findings we do not reject the null hypothesis that the combined project design factors have no significant influence on performance of Green Technology Market Projects in Meru County, Kenya and accept the alternative hypothesis that the combined project design factors have significant influence on performance of Green Technology Market Projects in Meru County, Kenya. Using the statistical findings, the regression model:

$$
\mathrm{Y}=\beta 0+\beta 1 \mathrm{X} 1+\beta 2 \mathrm{X} 2+\beta 3 \mathrm{X} 3+\beta 4 \mathrm{X} 4+\varepsilon
$$

The model can be substituted as follows:

$\mathrm{Y}=0.052+0.067 \mathrm{X} 1+0.046 \mathrm{X} 2+0.050 \mathrm{X} 3+0.040 \mathrm{X} 4+\varepsilon$
The beta value implies that for a one-unit increase in the project infrastructure, the performance of Green Technology Market project increases by 0.067 . A one-unit increase in Stakeholder Involvement, the performance of Green Technology Market project increases by 0.046 . A one-unit increase in Project Beneficiary Selection, the performance of Green Technology Market project increases by 0.050 and one-unit increase in Quality Management Practices, the performance of Green Technology Market project increases by 0.040 . Therefore, it confirms that combined project design factors have a significant influence on the performance of Green Technology Market projects.

Findings indicate that the Project design factors are key determinants for the performance of the Green Technology Market Projects. This agrees with [33] who posits that project Infrastructure is a key consideration and project donor ought to rally together all the paraphernalia in terms of resources to develop any project. The study confirmed that infrastructure facilities were diverse at the market.

The study found that stakeholders included the community leaders identified in a fair process which conforms to [34] stakeholders play various roles and responsibilities in a project's delivery which is directly proportional to project outcome. Further, the study observed that it's vital to involve benefactors in the project management team and also needs assessment to be done based on community priorities which are in line with work by [35] who echoes that the voice of benefactors in the project committee is a supreme tool to successful planning and also observed by [36] that project beneficiary needs analysis is important in project beneficiary selection process. The finding also shows that traders accessed quality services at the market. This agrees with work done by [37] who insinuates on the rationale of conniving projects with QM platforms is to enhance consumer contentment. The study also observed to a moderate extent that quality of services had improved with time for the last five years.

\section{CONCLUSION AND RECOMMENDATIONS}

The study sought to establish the influence of the project design factors on the performance of Green Technology Market Projects. From the findings, it can be concluded that project infrastructure, Stakeholders' involvement, project beneficiary selection and Quality Management Practices has a significant influence on the performance of Green Technology Market Projects and there is a strong association. This study concludes that proper combination of project design players is important to promote performance of Green Technology Market Projects. The study recommends that project stakeholders should pool resources to develop technological policies with recast on achieving the sustainable development goals that can spur technology uptake by our traders and project beneficiaries at large. The study also recommends that adoption of Green Technologies is an indispensable condition for the achievement of Sustainable development goals such as access to clean water, access to affordable and clean energy through robust infrastructure investment. Further, the study also recommends that project design drivers to contact the needs assessments based on community priorities to 
strengthen inclusivity, reduce inequality and enhance gender equality as away to achieve the sustainable development goals due to multi-stakeholders and benefactor's nature of such market projects. The study also recommends that quality assurance officers need training on quality standards with clear procedures on how to disseminate quality management practices to all parties in the market projects.

\section{ACKNOWLEDGMENT}

I wish to acknowledge Meru Traders Group more so the group leaders the Chairman, Secretary and Treasurer for their enormous support in mobilizing traders for interviews and responding to questionnaires. Furthermore, my gratitude goes to National Government Ministry of Trade officials and County Government of Meru officials from the ministry of Trade and Industrialization for their overwhelming support to retort to Questionnaires. Furthermore, I acknowledge my dear wife Elizabeth Nyambura Wembu, my two lovely sons Lavon Miles Barasa and Cephas Joseph Barasa for their financial support and encouragement during the study. Finally, I acknowledge the entire family of Ernest Barasa Wabwire and the late Gentrix Ajiambo Odundu for their awesome support in my study endeavors.

\section{REFERENCES}

[1] Prindle, B., Eldridge, M., Eckhardt, M., and Frederick, A. (2007) "The Twin Pillars of Sustainable Energy: Synergies between Energy Efficiency and Renewable Energy Technology and Policy". A CEEE Report Number E074, American Council for an Energy-Efficient Economy, Washington D.C.

[2] Maina, B. M. (2013). Influence of stakeholders' participation on the success of the economic stimulus programme: A case of education projects in Nakuru County, Kenya. Retrieved on 15th Aug 2016 from: http://erepository.uonbi. ac.ke:8080/xmlui/handle/12 3456789/56416.

[3] Freedman, D. A., Vaudrin, N., Schneider, C., Trapl, E., OhriVachaspati, P., Taggart, M., Ariel Cascio, M., Walsh, C., \& Flocke, S (2016). Systematic Review of Factors Influencing Farmers' Market Use Overall and among Low-Income Populations. Journal of the Academy of Nutrition and Dietetics.

[4] FAO (2012) The State of Food and Agriculture 2012 - Investing in Agriculture for a Better Farmers Markets

[5] Stephenson, G., L. Lev, and L. Brewer. 2008. Strategies for Taking Agricultural Successes to Scale in Sub-Saharan Africa.

[6] FAO (2012) The State of Food and Agriculture 2012 - Investing in Agriculture for a Better Farmers Markets.

[7] Freedman, D. A., Vaudrin, N., Schneider, C., Trapl, E., OhriVachaspati, P., Taggart, M., Ariel Cascio, M., Walsh, C., \& Flocke, S. (2016). Systematic Review of Factors Influencing Farmers' Market Use Overall and among Low-Income Populations. Journal of the Academy of Nutrition and DieteticsFuture.

[8] Kenya Gazette Supplement Number 56 (2011). Environmental Impact Assessment \& Audit Regulations 2003.Government Printer, Nairobi. 8. Kenya, the Urban Areas and Cities Act 2011.

[9] Kung'u, J.N., \& Mwangi, J.K. (2014). Effects of Fund Management Practices on Financial Performance in CDF funded Water Projects in Kenya. IOSR Journal of Economics and Finance, 5(3), 53-60.

[10] Govindasamy, R., Italia, J., \& Adelaja, A. (2002). Farmers' markets: Consumer trends, preferences, and characteristics. Journal of Extension [online], 40(1) Article 1RIB6.

[11] Food Marketing Institute Research. (2009). U.S. Grocery Shopper Trends. Arlington, VA.

[12] World Bank (2013) World Development Report 2013: Agriculture for Development, The World Bank,

[13] Kyalo, J.K., \& Muturi, W. (2015). Factors Affecting Completion of Government Funded Projects, a Survey of Projects in the Ministry of Water and Environment. Journal of Economics and Sustainable Development, 6 (8), 177184
[14] Ndirangu, M.D. (1994). Evaluation of infrastructural development in Nyeri town with emphasis to enhanced environmental Quality. University of Nairobi. M.A. Research Thesis.

[15] Ngesa, A.R. (2012). Influence of institutional factors in timely completion of infrastructure projects: A case of World Bank financed projects in the road sub- sector in Kenya. (Unpublished Master of Arts in Project Planning and Management Project, University of Nairobi, Nairobi, Kenya).

[16] Mbekeani, K. K. (2007). The Role of Infrastructure in Determining Export Competitiveness: Framework Paper. African Economics Research Consortium (AERC).

[17] Freedman, D. A., Vaudrin, N., Schneider, C., Trapl, E., OhriVachaspati, P., Taggart, M., Ariel Cascio, M., Walsh, C., \& Flocke, S (2016). Systematic Review of Factors Influencing Farmers' Market Use Overall and among Low-Income Populations. Journal of the Academy of Nutrition and DieteticsFuture.

[18] Witzling, L., B. Shaw, and D. Trechter. 2016. Wisconsin Consumers and Local Food: Public Opinion, Trends, and Marketing Recommendations. Madison, WI: University of Wisconsin Extension.

[19] Otekunrin, O. A. Smallholder Farmers' Market Participation: A Conceptual, Theoretical and Methodological Review. Unpublished $\mathrm{PhD}$ Non-Thesis Seminar presented in the Department of Agricultura Economics and Farm Management, Federal University of Agriculture, Abeokuta 2017

[20] Kenya Vision (2030).

[21] Wami K. I. (2012): Factors affecting the implementation of government ICT project (a case study of rivers state ICT department). Unpublished MSc. Thesis. Department of project management.

[22] Kikwatha R.W (2017) Project beneficiary process and sustainability of dairy goat projects in Kenya, International Journal of Research \& Innovation Vol.6 pg 146-148

[23] Sahoo, Pravakar (2011). Transport Infrastructure in India: Developments, Challenges Lessons from Japan. Published by Institute of Developing Economies, Japan External Trade Organization (IDEJETRO), 2011, No.465.

[24] Kikwatha R.W (2017) Project Infrastructure and sustainability of dairy goat projects in Kenya, International Journal of Research \& Innovation Vol.6

[25] Kikwatha R.W (2017) Project beneficiary process and sustainability of dairy goat projects in Kenya, International Journal of Research \& Innovation Vol.6 pg 146-148

[26] Swanepoel, H. \& DeBeers, F. (2006). Community development breaking the cycle of poverty 4th edition. Cape South Africa: Formeset Printers.

[27] Project Management Institute. (2012). A guide to the project management body of knowledge (PMBOK $\AA$ guide) (4th ed.) Newtown Square, PA: Project Management Institute.

[28] Lewis, S. (2015). Qualitative inquiry and research design: Choosing among five approaches. Health promotion practice, 16(4), 473-475.

[29] Goetsch D.L and S. B. Davis (2010). Quality Management for Organizational Excellence, Pearson, New Jersey, NJ, USA, 6th edition.

[30] Chepkirui, C. (2012). The role of strategic leadership in strategy implementation at the Agricultural Development Corporation (ADC) in Kenya (Doctoral dissertation, University of Nairobi, Kenya).

[31] Matiwane, M. \& Terblanché, E. (2012). The influence of beneficiaries needs on project success or failure in the northwest province, south Africa, Journal of Agriculture, \& Rural Development Vol. 40, 2012: $76-90$.

[32] Hines JM, Hungerford HR, Tomera AN (1987). Analysis and synthesis of research on responsible environmental behavior: A metaanalysis. The Journal of environmental education $18: 1-8$.

[33] Kikwatha R.W (2017) Project beneficiary process and sustainability of dairy goat projects in Kenya, International Journal of Research \& Innovation Vol.6

[34] Matiwane, M. \& Terblanché, E. (2012). The influence of beneficiaries needs on project success or failure in the northwest province, South Africa, Journal of Agriculture, \& Rural Development Vol. 40, 2012: $76-90$.

[35] Morales, A. 2009. "Public Markets as Community Development Tools." Journal of Planning

[36] Kikwatha R.W (2020) combined project design factors and sustainability of dairy goat projects in Kenya, International Journal of Research \& Innovation.

[37] Wiggins S (2012) 'Linking smallholders to markets: the issues' in Leaping and Learning. 


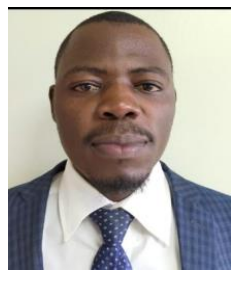

Mr. Silas Dennis Barasa was born in Busia County, Kenya in 1992. He holds a Masters of Arts degree in Project Planning and Management from University of Nairobi. He also holds a Bachelor of Science degree in Agriculture with specialization in Crop science from South Eastern Kenya University. Mr. Barasa is currently the founder of Agro-Space Research Technology where he serves as a Chief Consultant in Agribusiness project design and implementation. Mr. Barasa has over 4 years of experience in Banking \& Finance, as a Sales Executive and a Business Banker at Co-operative Bank of Kenya Ltd (Isiolo and Makutano) Branches. He also served as a board Teacher at St Patricks'Busibwabo and Lugulu A.C as a Biology \& Agriculture Teacher. $\mathrm{He}$ was initially an intern at Non-ruminant research centre, Kenya Agricultural and Livestock Research Organization (KALRO) Kakamega as a research assistant in Crop Production and Animal Husbandry.

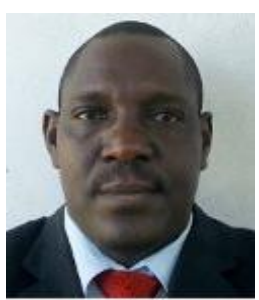

Dr Reuben Kikwatha was born in Kitui County, Kenya in 1975. He holds a doctorate in Project planning and Management, specializing in Project Planning Design, and Implementation from the University of Nairobi. He also holds a Masters degree in Project Planning and Management from The University of Nairobi, Bachelor's degree in Sociology from Moi University and a post graduate diploma in Community development.

Dr Kikwatha is currently a lecturer at the University of Nairobi, teaching project planning and Management in Open, Distance and eLearning (ODeL) campus, He has over 20 years of experience implementing Wildlife Conservation and community development projects in different parts of Kenya. Dr Kikwatha is a member of Kenya Association of Project Managers (KAPM) and Kenya Association of Fundraisers (KAF). $\mathrm{He}$ is also a member of different community development forums and academic mentorship groups. 